\title{
Basis Set Superposition Error on Structures and Complexation Energies of Organo-Alkali Metal Iodides
}

\author{
Chang Kon Kim, Hui Zhang, Sung Hoon Yoon, Jongok Won, ${ }^{\dagger}$ and Chan Kyung Kim* \\ Department of Chemistry, Inha University, Inchon 402-751, Korea. *E-mail: kckyung@inha.ac.kr \\ †Department of Chemistry, Sejong University, Seoul 134-747, Korea \\ Received May 19, 2010, Accepted June 15, 2010
}

\begin{abstract}
Theoretical studies have been performed to study the binding characteristics of the alkali metal iodides, $\mathbf{M}-\mathrm{I}(\mathbf{M}=\mathrm{Li}$, $\mathrm{Na}, \mathrm{K})$, to poly(ethylene oxide) (PEO, I), poly(ethylene amine) (PEA, II) and poly(ethylene $N$-methylamine) (PEMA, III) via the B3LYP method. In this study, two types of complexes, singly-coordinated systems (SCS) and doublycoordinated systems (DCS), were considered, and dissociation energies $\left(\triangle \mathrm{E}_{\mathrm{D}}\right)$ were calculated both with and without basis set superposition error (BSSE). Two types of counterpoise (CP) approach were investigated in this work, but the $\Delta E_{D}$ values corrected by using the function $\mathrm{CP}$ ( $\mathrm{fCP}$ ) correction exhibited an unusual trend in some cases due to deformation of the sub-units. This problem was solved by including geometry relaxation in the CP-corrected (GCP) interaction energy. On the other hand, the effects of the BSSE on the structures were very small when the complexes were re-optimized on the CP-corrected (RCP) potential energy surface (PES), even if the bond lengths between $\mathrm{X}$ and $\mathbf{M}^{+}\left(\mathrm{d}_{\mathrm{X}-\mathrm{M}^{+}}\right)$and between $\mathbf{M}^{+}$and I $\left(\mathrm{d}_{\mathrm{M}^{+}-\Gamma}\right)$ were slightly lengthened. Therefore, neither the GCP nor RCP corrections made much difference to the dissociation energies.
\end{abstract}

Key Words: Alkali metal iodides, Basis set superposition error, Dissociation energy, Density functional theory

\section{Introduction}

Polymer-based solid electrolytes with ionic conductivity have been targets of extensive studies because of their potential application as solid electrolytes in rechargeable batteries, fuel cells, etc. ${ }^{1}$ Polymer electrolytes typically consist of a metal salt and a polymer that functions as a solvent. Ionic conductivities in polymer electrolytes could therefore depend upon the interactions between ionic species of dissolved metal salts and polymeric ligands. The interaction between ionic species and polymeric ligands is thus an important factor in determining ionic conductivity, although this property also varies with the concentration of the dissolved metal salt and the mobility of the charge carriers. ${ }^{2}$

The interaction between ionic species and polymeric ligands corresponds to a complexation (or dissociation, in the inverse direction) process. Hence, related information such as complexation energy and/or structure can be predicted theoretically using the supermolecular approach. ${ }^{3}$ In this approach, the dissociation energy, $\Delta E_{D}$ in eq. (1), is simply estimated as the energy difference between the whole system and its subunits. In eq. (1), we follow the notation $E_{Y}^{Z}(\mathrm{X})$ to indicate the electronic energy of a molecular system $X$ at geometry $Y$ computed with basis set $Z$. However, it has been well known that one of the difficult problems in the simple supermolecular approach arises from the basis set superposition error (BSSE). That is, in the supermolecular approach, the interaction energy is artificially overestimated, because in this approach the intermolecular descriptions between subunits does not incorporate the basis functions of the partners. ${ }^{5}$ Therefore, in order to obtain accurate results corrected for BSSE, two methodologies, the counterpoise (CP) approach proposed by Boys and Bernardi ${ }^{6}$ and the Che- mical Hamiltonian Approach (CHA) developed by Mayer, ${ }^{7}$ have been commonly used. Moreover, even though the CHA and $\mathrm{CP}$ methodologies are conceptually very different, it has been well demonstrated that they tend to give similar results. ${ }^{8}$

$$
\Delta E_{D}=E_{A}^{A}(\mathrm{~A})+E_{B}^{B}(\mathrm{~B})-E_{A B}^{A B}(\mathrm{AB})
$$

In this work, the effects of the BSSE on dissociation processes in polymer electrolytes with alkali-metal iodides have been examined using the $\mathrm{CP}$ method. The function $\mathrm{CP}$ correction proposed by Boys and Bernardi ${ }^{6}, \triangle E_{D}(f C P)$ in eq. (2), determines a correction term that BSSE is minimized by using the same basis set for the equilibrium geometry as for the supermolecule and its subunits with fixed geometries of molecular systems, A and $\mathrm{B}$, at the supermolecule.

$$
\Delta E_{D}(f C P)=E_{A B}^{A B}(\mathrm{~A})+E_{A B}^{A B}(\mathrm{~B})-E_{A B}^{A B}(\mathrm{AB})
$$

Unfortunately, eqs. (1) and (2) will not converge to the same result, even if a complete basis set is used. Because the electronic energies of A and B are evaluated for different geometries of isolated and supermolecular systems, this problem can be solved by estimating the relaxation energies, eq. (3), required for distorting fragments $\mathrm{A}$ and $\mathrm{B}$ from their isolated geometries to the ones in the supermolecule. ${ }^{4,9}$ If the effects of geometry relaxation are considered, then the $\mathrm{CP}$-corrected interaction energy, $\triangle E_{D}(G C P)$, can be estimated by eq. (4).

$$
\begin{gathered}
E_{r e l}^{A}(A)=E_{A B}^{A}(\mathrm{~A})-E_{A}^{A}(\mathrm{~A}) \text { and } \\
E_{r e l}^{B}(B)=E_{A B}^{B}(\mathrm{~B})-E_{B}^{B}(\mathrm{~B})
\end{gathered}
$$




$$
\begin{aligned}
& \Delta E_{D}(G C P)= \\
& E_{A B}^{A B}(\mathrm{~A})+E_{A B}^{A B}(\mathrm{~B})-E_{A B}^{A B}(\mathrm{AB})-E_{r e l}^{A}(\mathrm{~A})-E_{r e l}^{B}(\mathrm{~B})
\end{aligned}
$$

However, it has been reported that the $\mathrm{CP}$ correction without considering geometrical effects often leads to physically incorrect terms. ${ }^{4,96}$ Therefore, in this work, the effects of $\mathrm{CP}$ corrections, $\triangle E_{D}(f C P)$ and $\triangle E_{D}(G C P)$, on uncorrected $\triangle E_{D}$ have been examined for the dissociation processes of complexes in polymer electrolytes. In polymer electrolytes, two types of dissociation processes, eqs. (5) and (6), are considered in the first step, where $\mathbf{P}, \mathbf{M}^{+}$, and I denote a polymeric ligand, a metal cation, and an iodide ion, respectively, and the resulting $\mathbf{P}-\mathbf{M}^{+}$ or $\mathbf{M}^{+}-\mathrm{I}^{-}$may be dissociated in the next stage.

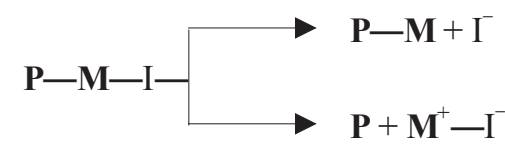

However, the dissociation of $\mathbf{M}^{+}-\mathrm{I}^{-}$to $\mathbf{M}^{+}$and $\mathrm{I}^{-}$corresponds to the simple heterolytic bond cleavages of molecular metal salts in a polymeric solvent, and the dissociations of $\mathbf{P}-\mathbf{M}^{+}$ for alkali metal cations have been reported in a previous work. ${ }^{10}$ Therefore, in this work, the first steps in the dissociation processes shown in eqs. (5) and (6) were studied for complexes consisting of a polymeric ligand and an alkali-metal iodide, $\mathbf{P}-$ $\mathbf{M}-\mathrm{I}$, where $\mathbf{P}=\mathrm{CH}_{3}-\mathrm{X}-\mathrm{CH}_{2}-\mathrm{CH}_{2}-\mathrm{X}-\mathrm{CH}_{3}(\mathrm{X}=\mathrm{O}, \mathrm{NH}$ and $\mathrm{N}$ $\mathrm{CH}_{3}$ ). These complexes have been selected as model systems for poly(ethylene oxide) (PEO, $\mathrm{X}=\mathrm{O}$ ), poly(ethylene amine) (PEA, $\mathrm{X}=\mathrm{NH}$ ) and poly(ethylene N-methylamine) (PEMA, $\mathrm{X}=$ $\mathrm{N}-\mathrm{CH}_{3}$ ), because these systems, having an iodide anion, could be potentially applied for polymer electrolytes in a solar cell, since, as is well known, the key function in the conventional dyesensitized solar cell (DSSE) is the electron transfer to an oxidized dye molecule by the iodide/triiodide electrolytes; thus, the concentration of free iodide anion could influence the efficiency of the DSSC. ${ }^{11}$ However, the studies on dissociation (or complexation) of iodide have been few, even though numerous works have been reported the iodide/triiodide redox potential in various materials. ${ }^{12}$ Therefore, in this work, the dissociation processes were considered in two structures, singly-coordinated (SCS) and doubly-coordinated structures (DCS), as represented in Scheme 1, since the type of coordination could be dependent on the concentration of dissolved salts. This study could provide useful information for the BSSE of the dissociation process of

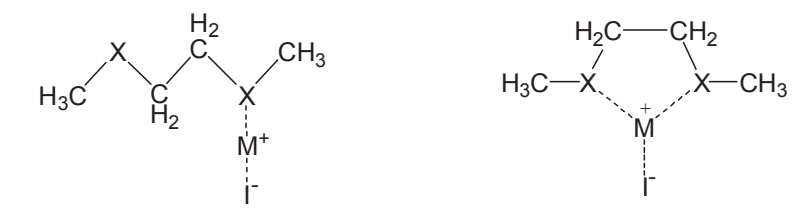

Singly-Coordinated System(SCS)

Doubly-Coordinated System(DCS)

where $\mathrm{X}=\mathrm{O}(\mathrm{I}), \mathrm{NH}(\mathrm{II})$, and $\mathrm{N}\left(\mathrm{CH}_{3}\right)$ (III) metal salts in polymer electrolytes.

\section{Computational Methods}

To examine the effects of the BSSE on optimized geometries, vibrational frequencies, and dissociation energies, the $\mathrm{CP}$-corrected and uncorrected structures of organo-alkali metal iodides were fully optimized and characterized by frequency calculations by using the Gaussian- 03 program. ${ }^{13}$ All calculations were carried out at the B3LYP level of theory with the 6-311++G(d,p) basis set, except for iodine. For iodine, a standard all-electron TZ-quality basis set ${ }^{14}$ augmented by a 2 -D polarization function with exponents of 0.30 and 0.08 , and one SP diffuse function with an exponent of 0.025 , were used. ${ }^{15}$ In this basis set, we used a split valence (SV) of 433321/43321/43, which we named the SV4PPD basis set, where PP stands for two polarization functions with exponents of 0.105 and $0.334 .{ }^{16}$ In our previous work on alkali-metal iodides, ${ }^{17}$ the combination of $6-311+\mathrm{G}(\mathrm{d})$ for alkali metals and a SV4PPD basis set for iodine at the B3LYP level gave reliable results for energetics and geometries compared to the experimental results.

\section{Results and Discussion}

The dissociation processes of iodide ion, eq. (5). The calculated dissociation energies $\left(\Delta E_{D}\right)$ of molecular alkali-metal iodides, $\mathbf{M}-\mathrm{I} \rightarrow \mathbf{M}^{+}$and $\mathrm{I}^{-}$, are $139.0,121.6$, and $105.0 \mathrm{kcal} \mathrm{mol}^{-1}$ for $\mathbf{M}=\mathrm{Li}, \mathrm{Na}$, and $\mathrm{K}$, respectively, indicating that the dissociation is in the order of difficulty $\mathrm{K}-\mathrm{I}<\mathrm{Na}-\mathrm{I}<\mathrm{Li}-\mathrm{I}$. ${ }^{18}$ Therefore, one may expect the dissociation processes of the iodide ion in the complexes formed from polymer alkali-metal iodides shown in eq. (5) to have a similar trend. The complexation energies $\left(\triangle E_{D}\right)$ of the SCSs and DCSs are shown in Table 1. The $\Delta E_{D}$ values shown in Table 1 revealed the same trend as those of molecular alkali-metal iodides in all cases, as expected. For example, the $\Delta E_{D}$ values increased in the order $\mathrm{I}-\mathrm{K}-\mathrm{I}<$ I- $\mathrm{Na}-\mathrm{I}<\mathrm{I}-\mathrm{Li}-\mathrm{I}$. However, the $\Delta E_{D}$ values in the SCSs were much smaller, by about $20\left(\mathrm{Li}^{+}\right) \sim 8\left(\mathrm{~K}^{+}\right)$, than those in the corresponding molecular alkali-metal iodides, since the polymer ligands stabilized the dissolved alkali-metal cations by electrostatic interaction. Moreover, the $\Delta E_{D}$ values in the DCSs were

Table 1. The calculated dissociation energies (in $\mathrm{kcal} \mathrm{mol}^{-1}$ ) for eq.

\begin{tabular}{|c|c|c|c|c|c|c|}
\hline & \multicolumn{3}{|c|}{ SCS } & \multicolumn{3}{|c|}{ DCS } \\
\hline & $\Delta E_{D}$ & $\begin{array}{c}\triangle E_{D} \\
(f C P)\end{array}$ & $\begin{array}{c}\Delta E_{D} \\
(G C P)\end{array}$ & $\Delta E_{D}$ & $\begin{array}{c}\Delta E_{D} \\
(f C P)\end{array}$ & $\begin{array}{c}\Delta E_{D} \\
(G C P)\end{array}$ \\
\hline I-Li-I & 121.4 & 119.7 & 118.7 & 108.4 & 107.9 & 105.9 \\
\hline $\mathrm{I}-\mathrm{Na}-\mathrm{I}$ & 109.9 & 109.4 & 108.2 & 101.6 & 100.9 & 99.8 \\
\hline $\mathrm{I}-\mathrm{K}-\mathrm{I}$ & 97.9 & 97.4 & 96.5 & 91.0 & 90.7 & 89.5 \\
\hline II- $\mathrm{Li}-\mathrm{I}$ & 119.2 & 118.0 & 116.5 & 106.3 & 107.7 & 103.8 \\
\hline $\mathrm{II}-\mathrm{Na}-\mathrm{I}$ & 109.0 & 110.0 & 106.9 & 100.4 & 102.2 & 98.4 \\
\hline II $-\mathrm{K}-\mathrm{I}$ & 98.0 & 99.2 & 96.2 & 93.3 & 94.4 & 91.3 \\
\hline III-Li-I & 117.9 & 116.8 & 115.0 & 106.8 & 105.7 & 104.0 \\
\hline III-Na-I & 107.2 & 106.0 & 105.1 & 100.5 & 99.3 & 98.3 \\
\hline III-K-I & 96.4 & 96.0 & 94.8 & 91.0 & 90.3 & 89.1 \\
\hline
\end{tabular}
(5) in the SCS and DCS complexes 
further decreased by about $10\left(\mathrm{Li}^{+}\right) \sim 5 \mathrm{kcal} \mathrm{mol}^{-1}\left(\mathrm{~K}^{+}\right)$as compared to the SCSs, due to stronger electrostatic interaction. Such effects could be one of the reasons why the metal salts were easily dissolved in polymer electrolytes.

The CP-corrected $\triangle \mathrm{E}_{\mathrm{D}}$ values, $\Delta E_{D}(f C P)$, could be expected to be smaller than the uncorrected $\Delta E_{D}$ values, because the artificially overestimated interactions in the supermolecular approaches were minimized by the $\mathrm{CP}$ corrections. In many cases, the $\triangle E_{D}(f C P)$ values seemed to decrease compared to the $\Delta E_{D}$ values, and the differences between two dissociation energies were small, within $c a .2 \mathrm{kcal} \mathrm{mol}^{-1}$. However, the $\triangle E_{D}(f C P)$ values were unexpectedly larger than those of the corresponding $\Delta E_{D}$ values in some complexes formed with II. For example, in II-K-I, the $\triangle E_{D}(f C P)$ values were larger by 1.2 (in the SCS) and 1.1 (in the DCS) $\mathrm{kcal} \mathrm{mol}^{-1}$ than the corresponding $\triangle E_{D}$ values. This result might be due to neglect of the effects of geometry relaxation, as shown in eq. (3). In general, when a larger basis set is employed, the calculated electronic energies are improved up to the Hartree-Fock limit. To explain this phenomenon, we can discuss the effects on the two fragments, $\mathbf{P}-\mathbf{M}^{+}$ (labeled A) and I (labeled B), separately. The calculated electronic energies for molecular units of $\mathbf{P}-\mathbf{M}^{+}$worsened going from $E_{A}^{A}(\mathrm{~A})$ to $E_{A B}^{A B}(\mathrm{~A})$ in all cases studied in this work, although the number of basis functions employed to calculate the $E_{A B}^{A B}(\mathrm{~A})$ was obviously larger than that employed to calculate the $E_{A}^{A}(\mathrm{~A})$. The changes in electronic energies going from $E_{A}^{A}(\mathrm{~A})$ to $E_{A B}^{A B}(\mathrm{~A})$ actually included both the unfavorable geometrical deformation $\left(\Delta E_{\text {def }}>0\right)$ and the favorable increase in the number of basis functions $\left(\Delta E_{\text {basis }}<0\right)$, i.e., $E_{A}^{A}(\mathrm{~A}) \stackrel{\Delta E_{d e f}>0}{\longrightarrow}$ $E_{A B}^{A}(\mathrm{~A}) \stackrel{\Delta E_{\text {basis }}<0}{\longrightarrow} E_{A B}^{A B}(\mathrm{~A})$. The $\Delta E_{\text {def }}$ and $\Delta E_{\text {basis }}$ are summarized in Table 2 . The calculated electronic energies therefore changed for the worse going from $E_{A}^{A}(\mathrm{~A})$ to $E_{A B}^{A B}(\mathrm{~A})$, since the $\Delta E_{\text {def }}$ values were larger than the $\left|\Delta E_{\text {basis }}\right|(\leq 0.2 \mathrm{kcal} / \mathrm{mol}$ in all cases). In the case of the counterion I, there was no geometrical deformation $\left(\Delta E_{\text {def }}=0\right)$, which meant that the calculated electronic energy improved on going from $E_{B}^{B}(\mathrm{~B})$ to $E_{A B}^{A B}(\mathrm{~B})$ due to the favorable $\Delta E_{\text {basis }}(-1.3 \sim-2.8 \mathrm{kcal} / \mathrm{mol})$. In any case, the $\triangle E_{D}(f C P)$ values included both effects of $E_{A}^{A}(\mathrm{~A}) \rightarrow E_{A B}^{A B}(\mathrm{~A})$ and $E_{B}^{B}(\mathrm{~B}) \rightarrow E_{A B}^{A B}(\mathrm{~B})$, and the favorable $\triangle E_{\text {basis }}$ were (fully or partially) cancelled out by the unfavorable $\Delta E_{\text {def. }}$. In other words, fCP corrections may be inadequate when the molecular unit(s) experience relatively large deformation.

In order to examine the $\mathrm{CP}$ corrections after removing the effects of deformation, the $\triangle E_{D}(G C P)$ values obtained from eq. (4) are also summarized in Table 1 . All the $\triangle E_{D}(G C P)$ values shown in Table 1 were smaller than the corresponding uncorrected $\Delta E_{D}$ values. This agrees well with the expectation that the $\mathrm{CP}$ correction minimizes the artificially overestimated molecular interaction in the supermolecular approach. Moreover, the differences between the $\triangle E_{D}(G C P)$ and $\triangle E_{D}$ values, $\delta \triangle E_{D}$ $(G C P)\left[=\Delta E_{D}-\Delta E_{D}(G C P)\right]$, for the SCSs were very similar to those for the corresponding DCSs, indicating that the CP corrections without geometrical deformation were similar for both cases. These results could be easily understandable - The $\delta \Delta E_{D}$ $(G C P)$ value was actually applicable to the pure basis set effect, $\triangle E_{\text {basis }}$, i.e., the $\delta \triangle E_{D}(G C P)$ could be represented as eq. (7) by subtracting eq. (1) from eq. (4). Therefore, the $\delta \triangle E_{D}(G C P)$ value
Table 2. The $\Delta E_{\text {def }}$ and $\Delta E_{\text {basis }}$ (in kcal mol ${ }^{-1}$ ) for eq. (5) in the SCS and DCS complexes

\begin{tabular}{lccccc}
\hline & \multicolumn{2}{c}{ SCS } & & \multicolumn{2}{c}{ DCS } \\
\cline { 2 - 3 } \cline { 5 - 6 } & $\Delta E_{\text {def }}$ & $\Delta E_{\text {basis }}$ & & $\Delta E_{\text {def }}$ & $\Delta E_{\text {basis }}$ \\
\hline I-Li-I & 1.0 & -2.7 & & 1.9 & -2.5 \\
I-Na-I & 1.2 & -1.7 & & 1.1 & -1.9 \\
I-K-I & 0.9 & -1.4 & & 1.2 & -1.6 \\
II-Li-I & 1.5 & -2.7 & & 3.8 & -2.5 \\
II-Na-I & 3.1 & -2.1 & & 3.8 & -2.1 \\
II-K-I & 3.0 & -1.9 & & 3.1 & -2.0 \\
III-Li-I & 1.9 & -2.9 & & 1.7 & -2.8 \\
III-Na-I & 0.9 & -2.1 & & 1.0 & -2.2 \\
III-K-I & 1.2 & -1.6 & & 1.2 & -1.8 \\
\hline
\end{tabular}

could be similar for the SCSs and the corresponding DCSs with the same basis set effects on the same subunits, $\mathrm{A}=\mathbf{P}-\mathbf{M}^{+}$and $\mathrm{B}=\mathrm{I}$, even if the structures are very different in the supermolecule, $\mathrm{AB}=\mathbf{P}-\mathbf{M}-\mathrm{I}$. On the other hand, the $\delta \Delta E_{D}(G C P)$ value decreased in the order $\mathbf{P}-\mathrm{Li}-\mathrm{I}>\mathbf{P}-\mathrm{Na}-\mathrm{I}>\mathbf{P}-\mathrm{K}-\mathrm{I}$ in both the SCSs and DCSs. This indicates that $\Delta E_{\text {basis }}$ values decreased as the number of basis functions increased in the $\mathbf{P}-\mathbf{M}^{+}$fragments, since contributions by the $\mathrm{I}^{-}$fragment were the same in all cases.

$$
\begin{aligned}
\delta & \Delta E_{D}(G C P) \\
& =\left\{E_{A B}^{A B}(\mathrm{~A})-E_{A B}^{A}(\mathrm{~A})\right\}+\left\{E_{A B}^{A B}(\mathrm{~B})-E_{A B}^{B}(\mathrm{~B})\right\} \\
& =\Delta E_{\text {basis }}(\mathrm{A})+\Delta E_{\text {basis }}(\mathrm{B})
\end{aligned}
$$

The dissociation processes of molecular alkali-metal iodides, eq. (6). The dissociation process shown in eq. (5) is a typical heterolytic bond fission requiring high energy, but the process shown in eq. (6) is a simple dissociation to neutral molecules, $\mathbf{P}$ and $\mathbf{M}-\mathbf{I}$ from $\mathbf{P}-\mathbf{M}-\mathbf{I}$. Therefore, the $\Delta E_{D}$ values for eq. (6) should be much smaller than those for eq. (5). The $\Delta E_{D}, \Delta E_{D}$ $(f C P)$ and $\triangle E_{D}(G C P)$ values of the SCSs and DCSs are shown in Table 3. The $\triangle E_{D}$ values shown in Table 3 were in the range of $10.9 \sim 25.9$ and $17.8 \sim 38.0 \mathrm{kcal} \mathrm{mol}^{-1}$ for the SCSs and DCSs, respectively, and smaller by ca. $80 \mathrm{kcal} \mathrm{mol}^{-1}$ than those for eq. (5), as expected. Nevertheless, the general trends were nearly the same as those found in eq. (5), i.e., the $\Delta E_{D}$ values decreased in the order $\mathbf{P}-\mathrm{Li}-\mathrm{I}>\mathbf{P}-\mathrm{Na}-\mathrm{I}>\mathbf{P}-\mathrm{K}-\mathrm{I}$, and the $\Delta E_{D}$ values for the DCSs were much larger than those for the corresponding SCSs.

On the other hand, as can be seen in Table 3, the $\triangle E_{D}(f C P)$ values in the SCSs were slightly smaller than the corresponding CP-uncorrected $\Delta \mathrm{E}_{\mathrm{D}}$ values, indicating that the $\left|\Delta E_{\text {basis }}\right|$ terms overweighed the unfavorable $\Delta E_{\text {def }}$ terms. However, in most cases of the DCSs, the $\triangle E_{D}(f C P)$ values were larger than the corresponding $\Delta E_{D}$ values, because the $\Delta E_{\text {def }}$ term was much larger than the $\left|\Delta E_{\text {basis }}\right|$ term, as shown in Table 4 . These results can easily be explained. In the DCSs, the M-I fragment interacted concurrently with two X sites of the ligand, and thus its structural deformation should be larger since the twisted bonds in the $\mathrm{X}-$ $\mathrm{CH}_{2}-\mathrm{CH}_{2}-\mathrm{X}$ fragment were released during the decomposi- 
Table 3. The calculated dissociation energies (in $\mathrm{kcal} \mathrm{mol}^{-1}$ ) for eq. (6) in the SCS and DCS complexes

\begin{tabular}{lrrrrrrrr}
\hline & \multicolumn{3}{c}{$\mathrm{SCS}$} & & \multicolumn{3}{c}{ DCS } \\
\cline { 2 - 5 } \cline { 7 - 8 } & $\Delta E_{D}$ & $\begin{array}{c}\Delta E_{D} \\
(f C P)\end{array}$ & $\begin{array}{c}\Delta E_{D} \\
(G C P)\end{array}$ & $\Delta E_{D}$ & $\begin{array}{c}\Delta E_{D} \\
(f C P)\end{array}$ & $\begin{array}{c}\Delta E_{D} \\
(G C P)\end{array}$ \\
\hline I-Li-I & 22.9 & 21.4 & 20.8 & & 34.8 & 35.8 & 32.2 \\
I-Na-I & 15.1 & 14.1 & 13.7 & & 25.1 & 24.9 & 22.9 \\
I-K-I & 10.9 & 10.4 & 9.9 & & 17.8 & 18.3 & 16.5 \\
II-Li-I & 25.9 & 24.5 & 23.8 & & 35.8 & 40.2 & 33.3 \\
II-Na-I & 18.7 & 18.0 & 16.8 & & 25.5 & 28.8 & 23.2 \\
II-K-I & 13.4 & 12.5 & 11.9 & & 19.2 & 22.9 & 17.3 \\
III-Li-I & 25.1 & 23.4 & 22.7 & & 38.0 & 38.6 & 35.2 \\
III-Na-I & 17.0 & 15.4 & 14.9 & & 26.9 & 26.3 & 24.3 \\
III-K-I & 11.7 & 10.8 & 10.3 & & 18.1 & 18.4 & 16.4 \\
\hline
\end{tabular}

Table 4. The $\Delta E_{\text {def }}$ and $\Delta E_{\text {basis }}$ (in kcal mol ${ }^{-1}$ ) for eq. (6) in the SCS and DCS complexes

\begin{tabular}{lccccc}
\hline & \multicolumn{2}{c}{ SCS } & & \multicolumn{2}{c}{ DCS } \\
\cline { 2 - 3 } \cline { 5 - 6 } & $\Delta E_{\text {def }}$ & $\Delta E_{\text {basis }}$ & & $\Delta E_{\text {def }}$ & $\Delta E_{\text {basis }}$ \\
\hline I-Li-I & 0.6 & -2.1 & & 3.7 & -2.7 \\
I-Na-I & 0.4 & -1.4 & & 2.0 & -2.2 \\
I-K-I & 0.4 & -1.0 & & 1.8 & -1.3 \\
II-Li一I & 0.7 & -2.1 & & 6.8 & -2.4 \\
II-Na-I & 1.2 & -1.9 & & 5.6 & -2.3 \\
II-K-I & 0.6 & -1.5 & & 5.6 & -1.9 \\
III-Li-I & 0.8 & -2.4 & & 3.4 & -2.9 \\
III-Na-I & 0.5 & -2.1 & & 2.1 & -2.6 \\
III-K-I & 0.4 & -1.3 & & 2.0 & -1.7 \\
\hline
\end{tabular}

tion processes (see Scheme 1). In the SCSs, however, there was no need to twist the bonds, since the $\mathbf{M}-$ I fragment interacted with only one $\mathrm{X}$ site of the ligand. As a result, the structural deformation during the decomposition processes was smaller in the SCSs than that in the DCSs.

Table 3 shows that the $\triangle E_{D}(G C P)$ values for the SCSs were smaller by $1.0 \sim 2.4 \mathrm{kcal} \mathrm{mol}^{-1}$ than the corresponding $\triangle E_{D}$ values. The differences, $\delta \triangle E_{D}(G C P)$, were very similar to those (1.4 2.9 $\mathrm{kcal} \mathrm{mol}^{-1}$ ) obtained from eq. (5), even if the $\Delta E_{D}$ values for eq. (5) were much larger than those for eq. (6). In the DCSs, the $\delta \triangle E_{D}(G C P)$ values obtained from eq. (6) (1.3 2.8

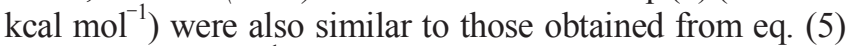
$\left(1.6 \sim 2.8 \mathrm{kcal} \mathrm{mol}^{-1}\right)$. Moreover, the $\delta \triangle E_{D}(G C P)$ values decreased in the same order, $\mathbf{P}-\mathrm{Li}-\mathrm{I}>\mathbf{P}-\mathrm{Na}-\mathrm{I}>\mathbf{P}-\mathrm{K}-\mathrm{I}$, in both cases. This indicated that the $\Delta E_{\text {basis }}$ values were similar for the dissociation processes described in eqs. (5) and (6). These results were somewhat confusing, since the dissociation modes were different, and the $\Delta E_{D}$ values were also very different from each other. Nevertheless, this could be easily understandable: the dissociation processes of eqs. (5) and (6) produced two different sub-units in the product side, $\mathrm{A}$ and $\mathrm{B}$, i.e., $\mathrm{A}=\mathbf{P}-\mathbf{M}^{+}$and $\mathrm{B}=\mathrm{I}^{-}$for eq. (5) and $\mathrm{A}^{\prime}=\mathbf{P}$ and $\mathrm{B}^{\prime}=\mathbf{M}-\mathrm{I}$ for eq. (6). However, the supermolecule was the same for both eqs., i.e., $\mathrm{AB}=\mathrm{A}^{\prime} \mathrm{B}^{\prime}=$
$\mathbf{P}-\mathbf{M}-\mathbf{I}$. Therefore, the $\delta \triangle E_{D}(G C P)$ values for eqs. (5) and (6) could be represented as eqs. (8) and (9), respectively, by modifying eq. (7). In eqs. (8) and (9), the number of basis sets for fragment A was obviously larger than that for the fragment A', since the fragment $\mathrm{A}\left(=\mathbf{P}-\mathbf{M}^{\dagger}\right)$ was larger in size than $\mathrm{A}^{\prime}(=\mathbf{P})$. This indicated that the basis set effect for $\mathrm{A}^{\prime}$ was larger than that for A since the same basis set $\mathrm{AB}$ was employed, i.e., $\Delta E_{\text {basis }}\left(\mathrm{A}^{\prime}\right)>$ $\Delta E_{\text {basis }}(\mathrm{A})$. On the contrary, for the fragments $\mathrm{B}\left(=\mathrm{I}^{-}\right)$and $\mathrm{B}^{\prime}$ $(=\mathbf{M}-\mathrm{I})$, the basis set effect was reversed, i.e., $\Delta E_{\text {basis }}(\mathrm{B})>$ $\Delta E_{\text {basis }}\left(\mathrm{B}^{\prime}\right)$. For example, in the dissociation process for the DCS complex of $\mathbf{I}-\mathrm{Li}-\mathrm{I}$, the $\Delta E_{\text {basis }}\left(\mathrm{A}=\mathbf{I}-\mathrm{Li}^{+}\right)$and $\Delta E_{\text {basis }}$ $\left(\mathrm{A}^{\prime}=\mathrm{I}\right)$ values were -0.1 and $-1.2 \mathrm{kcal} \mathrm{mol}^{-1}$, indicating that the basis set effect was larger by $1.1 \mathrm{kcal} \mathrm{mol}^{-1}$ for $\mathrm{A}^{\prime}$. However, the $\Delta E_{\text {basis }}\left(\mathrm{B}=\mathrm{I}^{-}\right)$and $\Delta E_{\text {basis }}\left(\mathrm{B}^{\prime}=\mathrm{LiI}\right)$ values were -2.4 and -1.5 $\mathrm{kcal} \mathrm{mol}^{-1}$, indicating that the basis set effect of B was $0.9 \mathrm{kcal}$ $\mathrm{mol}^{-1}$ larger than that of B'. Since these two effects were cancelled out, the $\delta \triangle E_{D}(G C P)$ values in eqs. (8) and (9) became similar. Therefore, the $\triangle E_{D}(G C P)$ could be more reliable than the $\triangle E_{D}(f C P)$ in correcting the pure basis set effects if the decomposition (or complexation) process produces different fragments from the same initial complex.

$$
\begin{aligned}
\delta & \Delta E(G C P, e q(5)) \\
& =\left\{E_{A B}^{A B}(\mathrm{~A})-E_{A B}^{A}(\mathrm{~A})\right\}+\left\{E_{A B}^{A B}(\mathrm{~B})-E_{A B}^{B}(\mathrm{~B})\right\} \\
& =\Delta E_{\text {basis }}(\mathrm{A})+\Delta E_{\text {basis }}(\mathrm{B}) \\
\delta & \Delta E(G C P, e q(6)) \\
& =\left\{E_{A B}^{A B}\left(\mathrm{~A}^{\prime}\right)-E_{A B}^{A^{\prime}}\left(\mathrm{A}^{\prime}\right)\right\}+\left\{E_{A B}^{A B}\left(\mathrm{~B}^{\prime}\right)-E_{A B}^{B^{\prime}}\left(\mathrm{B}^{\prime}\right)\right\} \\
& =\Delta E_{\text {basis }}\left(\mathrm{A}^{\prime}\right)+\Delta E_{\text {basis }}\left(\mathrm{B}^{\prime}\right)
\end{aligned}
$$

Effects of CP-corrections on the optimized geometries. The intermolecular distances between the ligands and alkali-metal iodides in the complexes could be lengthened when the CP correction is considered, since the overestimation in the intermolecular interaction is minimized. Therefore, in this work, the effects of the CP correction on the equilibrium geometries were examined by using the three cases of CP corrections; the complexes formed from (i) the two sub-units, $\mathbf{P}$ and $\mathbf{M}-\mathrm{I}$, (ii) the two sub-units, $\mathbf{P}-\mathbf{M}^{+}$and I, and (iii) the three sub-units, $\mathbf{P}, \mathbf{M}^{+}$ and $\mathrm{I}^{-}$. These calculations were performed using the counterpoise $=\mathrm{n}$ option in Gaussian 03 (where $\mathrm{n}$ refers to the number of fragments comprising the complex). The optimized bond lengths between $\mathrm{X}$ and $\mathbf{M}^{+}\left(\mathrm{d}_{\mathrm{X}-\mathrm{M}^{+}}\right)$and between $\mathbf{M}^{+}$and $\mathrm{I}^{-}\left(\mathrm{d}_{\mathrm{M}^{+}-\mathrm{\Gamma}}\right)$ are summarized in Figures 1 and 2. As expected, in the case of (iii) both the corrected $\mathrm{d}_{\mathrm{X}-\mathrm{M}^{+}}$and $\mathrm{d}_{\mathrm{M}^{+}-\Gamma}$ were lengthened compared to the uncorrected ones. Likewise, the corrected $\mathrm{d}_{\mathrm{X}-\mathrm{M}^{+}}$in the case of (i) and $\mathrm{d}_{\mathrm{M}^{+-}-\Gamma}$ in the case of (ii) were also lengthened as compared to the corresponding uncorrected ones.

However, interestingly, the corrected $\mathrm{d}_{\mathrm{M}^{+}-\Gamma}$ in the case of (i) was also lengthened slightly, except for $\mathrm{d}_{\mathrm{K}^{+-} \Gamma}$, even though we only considered the $\mathrm{CP}$ correction between $\mathrm{X}$ and $\mathbf{M}^{+}\left(\mathrm{d}_{\mathrm{X}-\mathrm{M}^{+}}\right)$. Similarly, the corrected $\mathrm{d}_{\mathrm{X}-\mathrm{M}^{+}}$in the case of (ii) was also lengthened in all cases, although we only considered the CP corrections between $\mathrm{M}^{+}$and $\mathrm{I}^{-}\left(\mathrm{d}_{\mathrm{M}^{+}-\Gamma}\right)$. In general, the $\mathrm{d}_{\mathrm{X}-\mathrm{M}^{+}}\left(\mathrm{d}_{\mathrm{M}^{+}-\mathrm{I}^{-}}\right)$ would be expected to be shortened when the $d_{M^{+}-\Gamma}\left(d_{X-M^{+}}\right)$was 

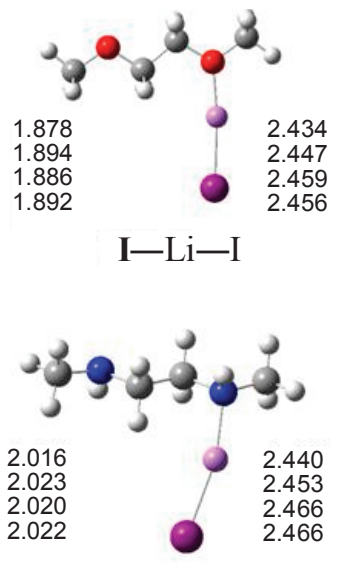

$$
\text { II-Li-I }
$$

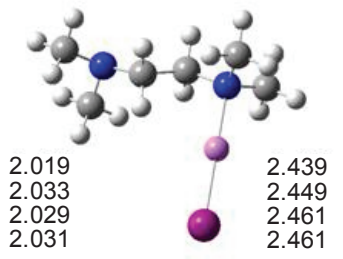

III-Li-I

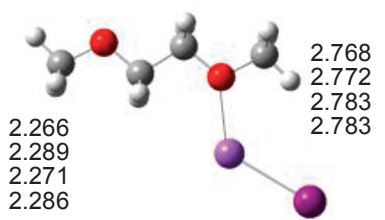

I-Na-I

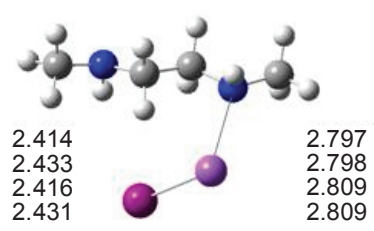

II- $\mathrm{Na}-\mathrm{I}$

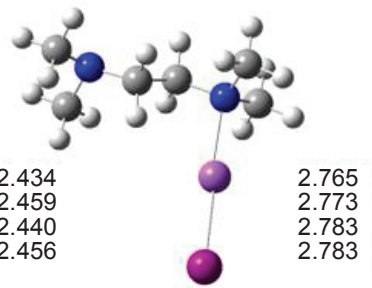

III- $\mathrm{Na}-\mathrm{I}$

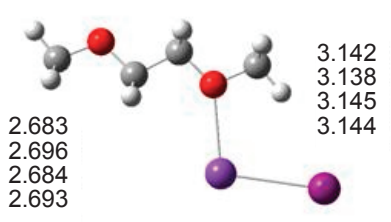

I-K-I

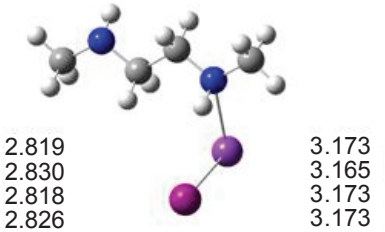

II-K-I

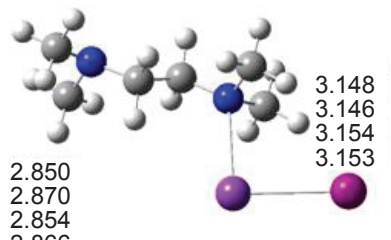

III-K-I

Figure 1. Optimized bond lengths (in $\AA$ ) using the three cases of CP corrections in the SCS. The values shown on the left and right sides of each structure are $\mathrm{dX}_{\mathrm{X}-\mathrm{M}^{+}}$and $\mathrm{d}_{\mathrm{M}^{+-} \mathrm{I}^{-}}$, respectively. From top to bottom, the bond lengths are shown in the order: CP-uncorrected, case (i), case (ii), and case (iii).

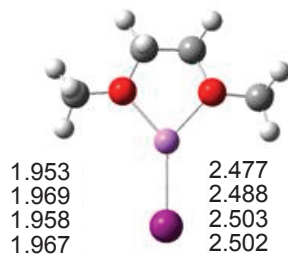

I-Li-I

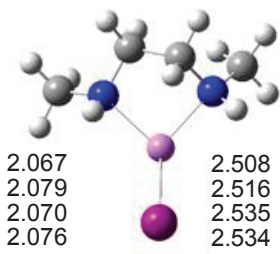

II-Li-I

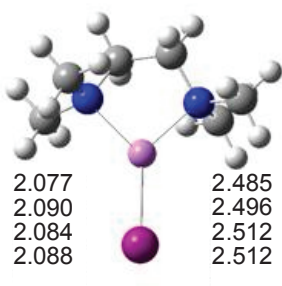

III-Li-I

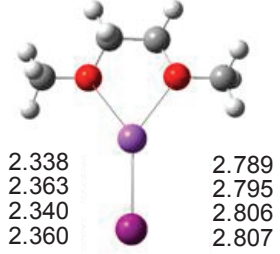

$\mathrm{I}-\mathrm{Na}-\mathrm{I}$
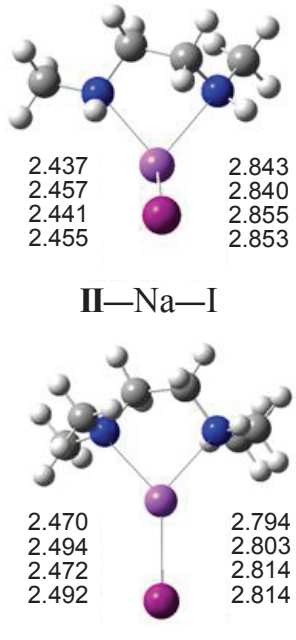

III-Na-I

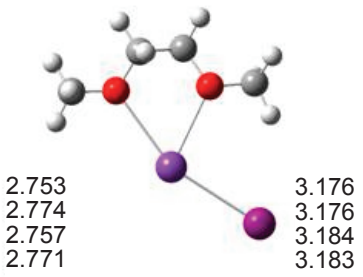

I-K-I
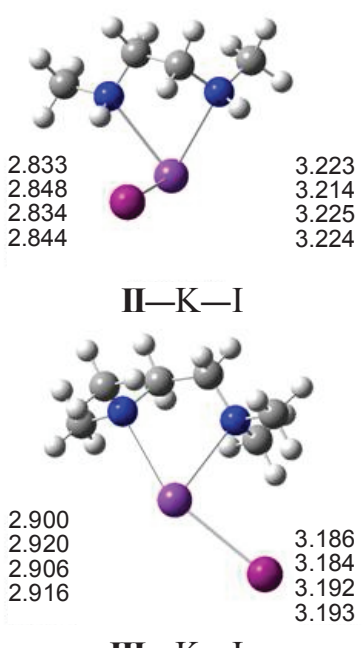

III-K-I

Figure 2. Optimized bond lengths (in $\AA$ ) using the three cases of CP corrections in the DCS. The values shown on the left and right sides of each structure are $\mathrm{d}_{\mathrm{X}-\mathrm{M}^{+}}$(average of two $\mathrm{dX}_{\mathrm{X}-\mathrm{M}^{+}}$values) and $\mathrm{d}_{\mathrm{M}^{+}-\mathrm{I}^{-}}$, respectively. From top to bottom, the bond lengths are shown in the order: CPuncorrected, case (i), case (ii), and case (iii). 
Table 5. The calculated dissociation energies (in $\mathrm{kcal} \mathrm{mol}^{-1}$ ) for the dissociation process of $\mathbf{P}-\mathbf{M}-\mathrm{I} \rightarrow \mathbf{P}+\mathbf{M}^{+}+\mathrm{I}^{-}$in the SCS and DCS complexes.

\begin{tabular}{lccccccc}
\hline & \multicolumn{3}{c}{$\mathrm{SCS}$} & & \multicolumn{3}{c}{$\mathrm{DCS}$} \\
\cline { 2 - 4 } \cline { 7 - 8 } & $\Delta E_{D}$ & $\begin{array}{c}\Delta E_{D} \\
(G C P)\end{array}$ & $\begin{array}{c}\Delta E_{D} \\
(R C P)\end{array}$ & $\Delta E_{D}$ & $\begin{array}{c}\Delta E_{D} \\
(G C P)\end{array}$ & $\begin{array}{c}\Delta E_{D} \\
(R C P)\end{array}$ \\
\hline I-Li-I & 161.9 & 158.6 & 158.7 & & 173.9 & 170.1 & 170.2 \\
I-Na-I & 136.7 & 134.4 & 134.4 & & 146.7 & 143.7 & 143.8 \\
I-K-I & 115.8 & 114.3 & 114.3 & & 122.8 & 120.9 & 120.9 \\
II-Li-I & 165.0 & 161.7 & 161.9 & & 174.8 & 171.4 & 171.4 \\
II-Na-I & 140.3 & 137.5 & 137.5 & & 147.1 & 144.0 & 144.1 \\
II-K-I & 118.4 & 116.3 & 116.5 & & 124.1 & 121.8 & 121.9 \\
III-Li-I & 164.1 & 160.7 & 160.8 & & 177.1 & 173.2 & 173.4 \\
III-Na-I & 138.5 & 135.7 & 135.8 & & 148.4 & 145.1 & 145.2 \\
III-K-I & 116.6 & 114.8 & 114.8 & & 123.0 & 120.8 & 120.9 \\
\hline
\end{tabular}

lengthened by the $\mathrm{CP}$ correction, because the bonding interaction between $\mathbf{P}$ and $\mathbf{M}^{+}\left(\mathbf{M}^{+}\right.$and I $)$in the complex was reinforced as the bonding interaction between $\mathbf{M}^{+}$and $\mathrm{I}^{-}\left(\mathbf{P}\right.$ and $\left.\mathbf{M}^{+}\right)$was weakened by the CP correction. Therefore, these results seemed to be strange at first sight: When the CP corrections between dimer and monomer units were considered for the hydrogenbonded water trimer, $\left(\mathrm{H}_{2} \mathrm{O}\right)_{3}$, and ammonia trimer, $\left(\mathrm{NH}_{3}\right)_{3}$, the interacting bond lengths in the dimers were shortened and the bond lengths between the dimers and monomers were lengthened, as would be expected. ${ }^{19}$ Similarly, in trimer complexes consisting of two neutral species and a cation, such as $\mathrm{C}_{2} \mathrm{H}_{4}---$ $\mathrm{M}^{+}---\mathrm{C}_{2} \mathrm{H}_{4}$, the same results were obtained. ${ }^{19}$ However, in the various trimers formed from the strong ionic-interactions such as $\left(\mathrm{CH}_{3}\right)_{2} \mathrm{O}---\mathbf{M}^{+}$--- $\mathbf{Y}^{-}$and $\mathrm{C}_{2} \mathrm{H}_{4}---\mathbf{M}^{+}---\mathbf{Y}^{-}$, where $\mathbf{M}^{+}$is a metal cation and $\mathbf{Y}^{-}$is a halide anion, the variations in the bond lengths as a result of the $\mathrm{CP}$ corrections were the same as those found in this work, i.e., when the CP corrections between $\mathbf{M}^{+}$and $\mathbf{Y}^{-}$ (or between neutral ligands and $\mathbf{M}^{+}$) were considered, both the bond lengths between neutral ligands and $\mathbf{M}^{+}$, and between $\mathbf{M}^{+}$and $\mathbf{Y}^{-}$were elongated simultaneously. ${ }^{19}$ These mysterious results may be due to the strong electrostatic interactions between cation and anion ligands in complexes containing an ionic species. Characterizing the effect of the $\mathrm{CP}$ corrections on the optimized geometries for a variety of trimer complexes is in progress in our lab.

For weak complexes having a flat potential energy surface (PES), some researchers have reported significant differences between the critical geometries of the BSSE-corrected and -uncorrected PESs. ${ }^{20}$ However, despite the changes in the bond lengths discussed above, the differences in the bond lengths between the corrected and the uncorrected, $\delta \mathrm{d}[=\mathrm{d}$ (corrected) $-\mathrm{d}$ (uncorrected)], were small (less than $0.02 \AA$ in most cases). Such small changes suggested that the effect of the CP correction on the optimized geometries of the supermolecule was also negligibly small. In other words, the dissociation energies calculated at the CP corrected PES, known as $\triangle E_{D}(R C P)$, were very similar to the $\triangle E_{D}(G C P)$ values obtained at the $\mathrm{CP}$ uncorrected PES due to small changes in molecular geometries. To confirm this, we examined the $\triangle E_{D}, \triangle E_{D}(G C P)$ and $\triangle E_{D}(R C P)$ values for the dissociation process of $\mathbf{P}-\mathbf{M}-\mathrm{I} \rightarrow \mathbf{P}+\mathbf{M}^{+}+\mathrm{I}^{-}$in Table 5.
This dissociation process could have the largest CP corrections, since the dissociation produced three subunits. As expected, the differences between the uncorrected $\triangle E_{D}$ and the corrected $\triangle E_{D}(G C P)$-i.e., the effects of the $\mathrm{CP}$ correction-were as large as about $1.5 \sim 4 \mathrm{kcal} \mathrm{mol}^{-1}$, but the differences between the $\triangle$ $E_{D}(G C P)$ and the $\triangle E_{D}(R C P)$ were negligibly small ( $c a .0 .1 \mathrm{kcal}$ $\mathrm{mol}^{-1}$ ). This implied that the CP method calculated from eq. 4 could be reliable for organo-alkali metal iodide complexes.

\section{Conclusions}

In the dissociation of organo-alkali metal iodides, the $\Delta E_{D}$ values increased in the order $\mathrm{I}-\mathrm{K}-\mathrm{I}<\mathrm{I}-\mathrm{Na}-\mathrm{I}<\mathrm{I}-\mathrm{Li}-\mathrm{I}$ for both the dissociation processes of eqs. (5) and (6). For the dissociation process of eq. (5), the $\Delta E_{D}$ values for the SCSs were much smaller than those for the corresponding molecular alkalimetal iodides, since the polymer ligands stabilized the dissolved alkali-metal cations by electrostatic interaction. The $\Delta E_{D}$ values for the DCSs were decreased further by about $10\left(\mathrm{Li}^{+}\right) \sim 5 \mathrm{kcal}$ $\mathrm{mol}^{-1}\left(\mathrm{~K}^{+}\right)$compared to the corresponding values for the SCSs due to a stronger electrostatic interaction. This stabilization effect could be one of the reasons why the metal salts dissolved easily in polymer electrolytes. On the other hand, when BSSE effects were considered, the fCP correction was found to be inadequate in some cases because of the large geometrical deformation caused by tight binding of the subunits, thus making the fCP corrections possibly inadequate when the molecular unit(s) experienced relatively large deformation. The incorporation of geometrical relaxation via the GCP method, as expressed in eq. (4), improved the results. When the molecular structures were re-optimized on the CP-corrected PES (the RCP method), the geometrical parameters showed no appreciable changes from the CP-uncorrected PES, and $\triangle E_{c}(G C P)$ was virtually the same as $\triangle E_{c}(R C P)$. This work again confirmed the capacity of the GCP method to generate reliable results in the study of the organo-alkali metal complexes.

Acknowledgments. This research was supported by the Basic Research Program through the National Research Foundation of Korea (NRF) funded by the Ministry of Education, Science and Technology (KRF-2007-314-C00137), in which the main calculations were performed by using the supercomputing resource of the Korea Institute of Science and Technology Information (KISTI).

\section{References}

1. (a) Gray, F. M. In Polymer Electrolytes; Connor, J. A., Ed.; The Royal Society of Chemistry: London, 1997. (b) Ferry, A.; Orädd, G.; Jacobsson, P. J. Chem. Phys. 1998, 108, 7426.

2. (a) Watanabe, M.; Ogata, N. in Polymer Electrolyte Reviews; MacCallum, J. R., Vincent, C. A., Eds.; Elsevier: London, 1987. (b) Won, J.; Lee, K. M.; Kang, Y. S.; Chang, S.-K.; Kim, C. K.; Kim, C.-K. Macromol. Res. 2006, 14, 404.

3. Chalasiński, G.; Szczęśniak, M. M. Chem. Rev. 1994, 94, 1723.

4. Xantheas, S. S. J. Chem. Phys. 1996, 104, 8821.

5. (a) Jensen, H. B.; Ross, P. Chem. Phys. Lett. 1969, 3, 140. (b) Boys, S. F.; Bernardi, F. Mol. Phys. 1970, 19, 553. (c) Liu, B.; McLean, A. D. J. Chem. Phys. 1973, 59, 4557.

6. Boys, S. F.; Bernadi, F. Mol. Phys. 1970, 19, 553. 
7. Mayer, I. Int. J. Quantum Chem. 1983, 23, 341 .

8. (a) Mayer, I. Int. J. Quantum Chem. 2004, 100, 59. (b) Salvador, P.; Paizs, B.; Duran, M.; Suhai, S. J. Comput. Chem. 2001, 22, 765.

9. (a) Daza, M. C.; Dobado, J. A.; Molina, J. M.; Salvador, P.; Duran, M.; Villaveces, J. L. J. Chem. Phys. 1999, 110, 11806. (b) Siu, F. M.; Ma, N. L.; Tsang, C. W. J. Chem. Phys. 2001, 114, 7045.

10. Kim, C. K.; Zhang, H.; Yoon, S. H.; Won, J.; Lee, M.-J.; Kim, C. K. J. Chem. Phys. A 2009, 113, 513.

11. (a) Zhang, Z.; Ito, S.; Moser, J.-E.; Zakeeruddin, S. M.; Grätzel, M. ChemPhysChem 2009, 10, 1834. (b) Yanagida, S.; Yu, Y.; Manseki, K. Acc. Chem. Res. 2009, 42, 1827.

12. (a) Nasr, C.; Hotchandani, S.; Kamat, P. J. Chem. Phys. B 1998, 102, 4944. (b) Mwaura, J. K.; Zhao, X.; Jiang, H.; Schanze, K. S.; Reynolds, J. R. Chem. Mater. 2006, 18, 6109. (c) Grätzel, M. Nature 2001, 414, 338. (d) Günes, S.; Neugebauer, H.; Sariciftci, N. S. Chem. Rev. 2007, 107, 1324.

13. Frisch, M. J.; Trucks, G. W.; Schlegel, H. B.; Scuseria, G. E.; Robb, M. A.; Cheeseman, J. R.; Montgomery, J. A., Jr.; Vreven, T.; Kudin, K. N.; Burant, J. C.; Millam, J. M.; Iyengar, S. S.; Tomasi, J.; Barone, V.; Mennucci, B.; Cossi, M.; Scalmani, G.; Rega, N.; Petersson, G. A.; Nakatsuji, H.; Hada, M.; Ehara, M.; Toyota, K.; Fukuda, R.; Hasegawa, J.; Ishida, M.; Nakajima, T.; Honda, Y.; Kitao, O.; Nakai, H.; Klene, M.; Li, X.; Knox, J. E.; Hratchian, H. P.; Cross, J. B.; Adamo, C.; Jaramillo, J.; Gomperts, R.; Stratmann, R. E.; Yazyev, O.; Austin, A. J.; Cammi, R.; Pomelli, C.; Ochterski, J. W.; Ayala, P. Y.; Morokuma, K.; Voth, G. A.; Salvador, P.; Dannenberg, J. J.; Zakrzewski, V. G.; Dapprich, S.; Daniels, A. D.;
Strain, M. C.; Farkas, O.; Malick, D. K.; Rabuck, A. D.; Raghavachari, K.; Foresman, J. B.; Ortiz, J. V.; Cui, Q.; Baboul, A. G.; Clifford, S.; Cioslowski, J.; Stefanov, B. B.; Liu, G.; Liashenko, A.; Piskorz, P.; Komaromi, I.; Martin, R. L.; Fox, D. J.; Keith, T.; AlLaham, M. A.; Peng, C. Y.; Nanayakkara, A.; Challacombe, M.; Gill, P. M. W.; Johnson, B.; Chen, W.; Wong, M. W.; Gonzalez, C.; Pople, J. A. Gaussian 03, Revision B03. Gaussian, Inc., Pittsburgh PA, 2003.

14. Poirier, R.; Kari, R.; Csizmadia, I. G. Handbook of Gaussian Basis Sets; Elsevier: Amsterdam, 1985.

15. Wiberg, K. B.; Sklenak, S. Organometallics 2001, $20,771$.

16. Andzelm, J.; Klobukowski, M.; Radzio-Andzelm, E. J. Comput. Chem. 1984, 5, 146 .

17. Kim, C. K.; Yoon, S. H.; Won, J.; Kim, C. K. Bull. Korean Chem. Soc. 2006, 27, 1219.

18. The calculated dissociation enthalpies $\left(\Delta H_{D}\right)$ at $298 \mathrm{~K}$ were 139.1 , 121.8 and $105.7 \mathrm{kcal} \mathrm{mol}^{-1}$ for $\mathrm{Li}-\mathrm{I}, \mathrm{Na}-\mathrm{I}$ and $\mathrm{K}-\mathrm{I}$, respectively, and these were well agreed with the experimental ones. The experimental $\Delta H_{D}$ values were $139.1,118.3$ and $106.3 \mathrm{kcal} \mathrm{mol}^{-1}$ (Miehlich, B.; Savin, A.; Stoll, H.; Preuss, H. Chem. Phys. Lett. 1989, 157, 200).

19. Kim, C. K.; Won, J.; Kim C. K. Unpublished results.

20. (a) Hugas, D.; Simon, S.; Duran, M. Chem. Phys. Lett. 2004, 386, 373. (b) Salvador, P.; Duran, M.; Dannenberg, J. J. J. Phys. Chem. A 2002, 106, 6883. (c) Paizs, B.; Salvador, S.; Császár, A. G.; Duran, M.; Suhai, S. J. Comput. Chem. 2001, 22, 196. (d) Simon, S.; Duran, M.; Dannenberg, J. J. J. Chem. Phys. 1996, 105, 11204. 